\title{
Toxic colonoscopy-how investigating active inflammatory bowel disease can lead to the serious complication of toxic megacolon
}

\author{
Shohib Tariq, ${ }^{1}$ Assad Farooq, ${ }^{1}$ Ibrar Ali, $^{2}$ Haren Wijesinghe ${ }^{3}$
}

${ }^{1}$ University Hospital of North Midlands NHS Trust, Stafford, West Midlands, UK

${ }^{2}$ Heart of England Foundation Trust, Birmingham, West Midlands, UK

${ }^{3}$ University Hospital Birmingham, Queen Elizabeth, Birmingham, West Midlands, UK

\section{Correspondence to}

Dr Shohib Tariq, shohib.tariq@nhs.net

Accepted 9 July 2015
CrossMark

To cite: Tariq $S$, Faroog $A$, Ali I, et al. BMJ Case Rep Published online: [please include Day Month Year] doi:10.1136/bcr-2015209769

\section{DESCRIPTION}

A 15 -year-old girl presented to accident and emergency A\&E unable to cope after a week-long history of abdominal pain with vomiting and blood-streaked diarrhoea.

The patient had been known to the gastroenterologist for suspected inflammatory bowel disease and was due for an outpatient endoscopy.

On examination, the patient was febrile and tachycardic. There were no mouth ulcers or skin changes, however, finger clubbing was present, there was guarding and the patient was tender in all quadrants. There were no palpable masses or evidence of organomegaly. Bowel sounds were present.

The patient had been using a hot water bottle, which had caused erythema ab igne.

The patient was expedited for oesophagogastroduodenoscopy and colonoscopy (figure 1) after having bowel preparation. Results displayed antral gastritis and severe colitis with cobblestoning and pseudopolyposis-like mucosal oedema.

The following day, there was a severe increase in pain and abdominal distension with bowel sounds

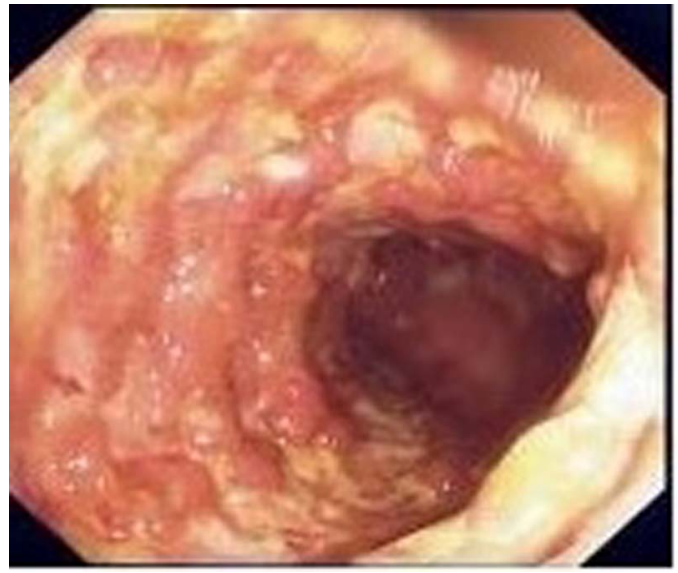

Figure 1 Results displayed antral gastritis and severe colitis with cobblestoning and pseudopolyposis-like mucosal oedema. absent. Abdominal radiograph (figure 2) showed dilated bowel and CT scanning confirmed toxic megacolon (figures 3 and 4), although no perforation.

The patient was made nil by mouth; hydrocortisone, intravenous cefotaxime and metronidazole were started as per guidelines.

With pain improving the following day and radiology showing improvement in dilation, diet was reintroduced once bowel sounds returned.

There is evidence to suggest colonoscopy ${ }^{2}$ and bowel preparation ${ }^{3}$ may have caused the exacerbation of ulcerative colitis leading to toxic megacolon.

It is important to ensure patients who have not currently undergone diagnostic colonoscopy for inflammatory bowel disease do not have the procedure during a flare up as is evident here.

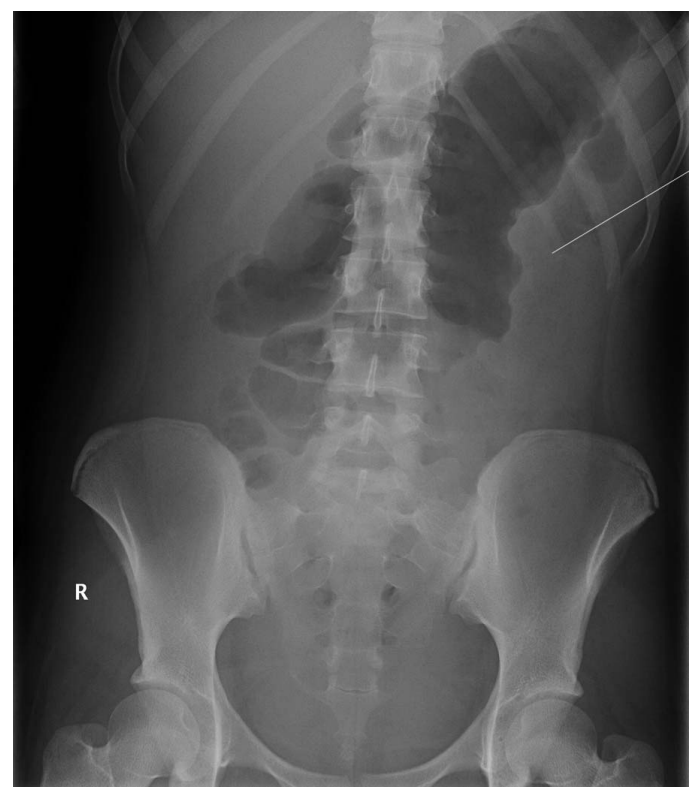

Figure 2 Plain abdominal radiograph where the transverse colon shows evidence of thumb printing in keeping with bowel wall oedema along with marked dilation. It was vital to reduce the dilation as serious complications include perforation and sepsis. 


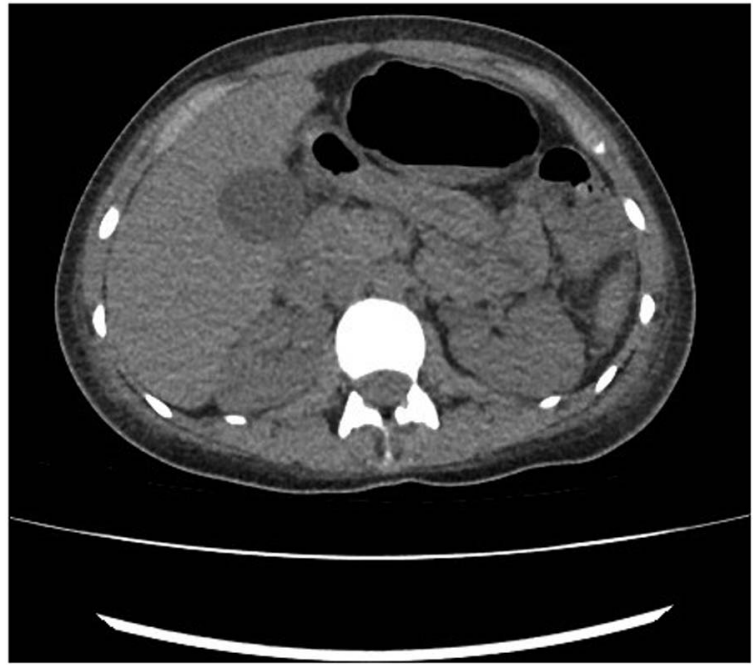

Figure 3 Axial view of CT abdomen image showing abnormally dilated colon measuring up to $7.2 \mathrm{~cm}$ in diameter, which is consistent with the appearance of toxic megacolon.

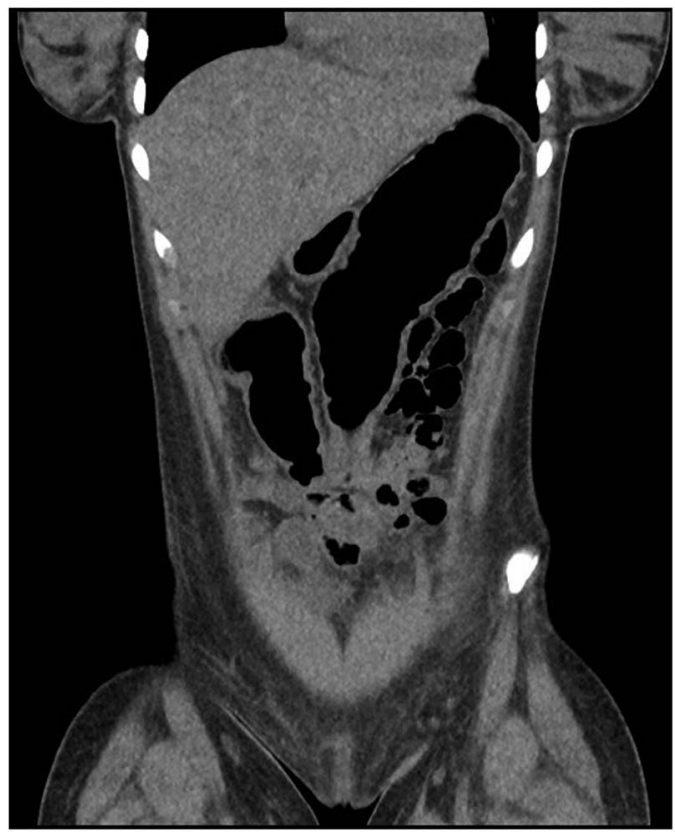

Figure 4 Coronal view of the toxic colon.

\section{Learning points}

- Acute exacerbation of inflammatory bowel disease should be treated with caution and endoscopic procedures should be avoided, however, if they are necessary, laxative-based bowel preparation formulas should be used with caution pre-endoscopy as they are both hypothesised causes for the development of toxic megacolon. There is great importance in the early recognition of toxic megacolon as this can be fatal in the instance of bowel perforation or could lead to the loss of bowel causing significant detrimental lifestyle changes.

- In lieu of colonoscopy, clinical scoring systems exist to predict the progression of inflammatory bowel disease activity, which can be used to direct the initiation of treatment in the case of an acute flare up. In this case, the Paediatric Ulcerative Colitis Activity Index (PUCAI) can be used. The PUCAI is calculated using signs and symptoms, and the maximum score is 85 . This patient had a score of $80 / 85$-in keeping with the results of the colonoscopy.

- The link concerning bowel preparation with toxic megacolon is unidentified; however, electrolyte disturbances and acute inflammation are hypothesised to lead to reduced colonic muscle tone, and, therefore, dilation. The alternative explanation is the colonoscopy itself further irritates the colon leading to inflammation and toxic megacolon.

Contributors ST gained consent, gathered the clinical information for the case, was involved in the diagnostic process and assisted with the write up of the case. AF supervised and critically reviewed the article for intellectual content, was involved in radiological analysis and assisted with the write up of the case. IA and HW were involved with the conception and design of the manuscript and a review of the literature, and assisted with the write up of the case.

Competing interests None declared.

Patient consent Obtained.

Provenance and peer review Not commissioned; externally peer reviewed.

\section{REFERENCES}

1 Strong SA. Management of acute colitis and toxic mega colon. Clin Colon Rectal Surg 2010;23:274-84.

2 Menees $S$, Higgins $P$, Korsnes $S$, et al. Does colonoscopy cause increased ulcerative colitis symptoms? Inflamm Bowel Dis 2007;13:12-8.

3 Caprilli $\mathrm{R}$, Vernia $\mathrm{P}$, Colaneri 0 , et al. Risk factors in toxic megacolon. Dig Dis Sc 1980;25:817-22

Copyright 2015 BMJ Publishing Group. All rights reserved. For permission to reuse any of this content visit http://group.bmj.com/group/rights-licensing/permissions.

BMJ Case Report Fellows may re-use this article for personal use and teaching without any further permission.

Become a Fellow of BMJ Case Reports today and you can:

- Submit as many cases as you like

- Enjoy fast sympathetic peer review and rapid publication of accepted articles

- Access all the published articles

- Re-use any of the published material for personal use and teaching without further permission

For information on Institutional Fellowships contact consortiasales@bmjgroup.com

Visit casereports.bmj.com for more articles like this and to become a Fellow 